\title{
Precipitation of Zinc Oxide Nanoparticles in Bicontinuous Microemulsions
}

\author{
Liliana E. Romo, Hened Saade, Bertha Puente, Ma. Luisa López, \\ Rebeca Betancourt, and Raúl G. López \\ Centro de Investigación en Química Aplicada, Boulevard Enrique Reyna Hermosillo No. 140, 25253 Saltillo, Coah, Mexico \\ Correspondence should be addressed to Raúl G. López, glopez@ciqa.mx
}

Received 13 August 2011; Accepted 8 September 2011

Academic Editor: Anukorn Phuruangrat

Copyright (C) 2011 Liliana E. Romo et al. This is an open access article distributed under the Creative Commons Attribution License, which permits unrestricted use, distribution, and reproduction in any medium, provided the original work is properly cited.

\begin{abstract}
Zinc oxide nanoparticles were obtained directly, avoiding the calcination step, by precipitation at $70^{\circ} \mathrm{C}$ in bicontinuous microemulsions stabilized with a mixture of surfactants sodium bis (2-ethylhexyl) sulfosuccinate/sodium dodecyl sulfate (2/1, wt./wt.) containing $0.7 \mathrm{M}$ zinc nitrate aqueous solution. Two concentrations of aqueous solution of precipitating agent sodium hydroxide were used under different dosing times on microemulsion. Characterization by X-ray diffraction and electron microscopy allowed us to identify particles with an acicular rod-like morphology and a hexagonal wurtzite crystal structure as small as 8.5 and $30 \mathrm{~nm}$ in average diameter and length, respectively. Productivities much higher than those typical in the preparation of zinc oxide nanoparticles via reverse microemulsions were obtained. Particle size was the same at the two studied sodium hydroxide concentrations, while it increases as dosing time of the precipitant agent increases. It is believed that the surfactant film on the microemulsion channels restricts the particle diameter growth.
\end{abstract}

\section{Introduction}

Zinc oxide $(\mathrm{ZnO})$ nanoparticles are a very interesting material because of their practical applications in the construction of electronic, optical, and acoustic devices [1], as well as their bactericidal properties $[2,3]$, among others. In the latter, the great surface area/volume of nanoparticles makes them more attractive than those of larger size. Under the same conditions, a given quantity of $\mathrm{ZnO}$ nanoparticles $10 \mathrm{~nm}$ in diameter would release ten times the ions released by the same quantity of particles $100 \mathrm{~nm}$ in diameter.

Various methods for preparing $\mathrm{ZnO}$ nanoparticles have been investigated such as sol-gel process $[4,5]$, chemical coprecipitation $[6,7]$, chemical vapor deposition [8], thermal decomposition $[9,10]$, hydrothermal synthesis [11], solid-state reaction [12], spray pyrolysis [13], and microemulsion precipitation [14-18]. These methods have allowed to obtain various $\mathrm{ZnO}$ structures such as nanospheres, nanorods, nanowires, and nanotubes.

Precipitation in reverse microemulsions usually leads to particles with an average diameter smaller than $10 \mathrm{~nm}$ and low particle size polydispersity $[19,20]$. However, the preparation of $\mathrm{ZnO}$ nanoparticles by this method has been scarcely investigated [14-18]. According to these reports, $\mathrm{ZnO}$ nanoparticles with average diameters from $5-15 \mathrm{~nm}$ [14$16,18]$ to $\approx 150 \mathrm{~nm}[17]$ have been obtained. In the early nineties, synthesis of $\mathrm{ZnO}$ nanoparticles via reverse microemulsions was first reported by the group of Shah [14, 15]. These authors mixed two reverse microemulsions, one containing a zinc nitrate aqueous solution and the other, an ammonium carbonate aqueous solution, to obtain zinc carbonate nanoparticles. Further calcination of this compound leaded to spheroidal nanoparticles of $\mathrm{ZnO}$ with $14 \mathrm{~nm}$ in average diameter. Later, the same group published the use of reverse microemulsions stabilized with zinc (bis etylhexyl) sulfosuccinate (synthesized by the authors) to precipitate zinc oxalate by adding oxalic acid. $\mathrm{ZnO}$ nanoparticles of about $5-13 \mathrm{~nm}$ in diameter were obtained by zinc oxalate calcination [16]. The preparation of $\mathrm{ZnO}$ particles via bicontinuous microemulsions was first reported by the group of Gan [17]. A solution of sodium hydroxide was added to a microemulsion containing a zinc nitrate aqueous solution 
to precipitate zinc hydroxide, which was further calcined to obtain spherical shaped-ZnO particles. However, these particles were very large (ca. $150 \mathrm{~nm}$ in diameter). This unusually large particle sizes obtained via microemulsion precipitation was ascribed by the authors to grain growth and particle agglomeration during the calcination process. More recently, Inoguchi et al. [18] reported the preparation of spherical shaped $\mathrm{ZnO}$ nanoparticles as small as $5 \mathrm{~nm}$ in average diameter. These particles were obtained by direct precipitation in a reverse microemulsion containing an aqueous solution of sodium hydroxide to which an alcoholic solution of zinc diethoxide was added.

In the quoted works on preparation of $\mathrm{ZnO}$ particles via microemulsion, data on the productivity of the used process are not included. However, calculations carried out from available data in those documents show theoretical productivity, in $\mathrm{g}$ of $\mathrm{ZnO}$ per $100 \mathrm{~g}$ of microemulsion, ranging from $0.2[14,15]$ and $0.7[17]$ to 2.0 [16]. It is noteworthy that the highest productivity was obtained using a noncommercial surfactant, which was synthesized by a somewhat complex route.

Higher productivity in microemulsion precipitation can be achieved by using bicontinuous microemulsions [2123]. Unlike reverse microemulsions, which contain low aqueous phase concentrations (normally $\leq 15 \mathrm{wt} \%$ ), bicontinuous microemulsions can have up to $40-50 \mathrm{wt} \%$ [24]. This is due to differences in nanostructure; while reverse microemulsions are made up of nanodroplets of the aqueous phase dispersed in an oleic continuous phase, bicontinuous microemulsions are formed by interconnected aqueous channels with diameters usually less than $10 \mathrm{~nm}$, immersed in an oleic continuous phase [24]. Because of the higher aqueous phase concentration (where precipitation reactions occur), it is expected that an increase in the productivity of precipitated nanoparticles could be achieved through the use of bicontinuous microemulsions.

In this paper, we report the use of bicontinuous microemulsions as media for precipitating $\mathrm{ZnO}$ nanoparticles in a direct way, which avoids the calcination step. To our best knowledge, this is the first document in the specialized literature reporting this fact. Microemulsions containing aqueous solution of zinc nitrate and toluene as organic phase were stabilized with the mixture of surfactants sodium bis (2-ethylhexyl) sulfosuccinate (AOT)/sodium dodecylsulfate (SDS), in a weight ratio of $2 / 1$. Precipitation reactions were carried out at $70^{\circ} \mathrm{C}$ by dosing an aqueous solution of sodium hydroxide to the microemulsions. We studied the effect on morphology and particle size of concentration of sodium hydroxide solution and its addition on microemulsion at different dosing times.

\section{Materials and Methods}

2.1. Materials. Zinc nitrate hexahydrated $\left(\mathrm{Zn}\left(\mathrm{NO}_{3}\right)_{2} \cdot 6 \mathrm{H}_{2} \mathrm{O}\right.$, $99 \%)$, SDS (>98.5\%) and toluene (>99.8\%) from Aldrich as well as AOT (>96\%) from Fluka and $\mathrm{NaOH}(98.9 \%)$ from Fermont were used as received. Water was of tridistilled deionized grade.
2.2. Precipitation Reactions. All the precipitation reactions were performed in duplicate (set 1 and set 2 ) at $70^{\circ} \mathrm{C}$ in a $100 \mathrm{~mL}$ jacketed glass reactor equipped with a reflux condenser and inlets for the microemulsion and $\mathrm{NaOH}$ aqueous solution feed. Composition of the bicontinuous microemulsions was the same in all precipitation reactions, and it was chosen based on electrical conductivity and rheological measurements of selected samples of mixtures AOT/SDS (2/1, wt./wt.), $0.7 \mathrm{M} \mathrm{Zn}\left(\mathrm{NO}_{3}\right)_{2} \cdot 6 \mathrm{H}_{2} \mathrm{O}$ aqueous solution and toluene. The chosen microemulsion was composed of 40.5 wt.\% surfactant, 32.5 wt.\% $0.7 \mathrm{M}$ zinc nitrate aqueous solution, and $27 \mathrm{wt} . \%$ toluene. The typical procedure for the precipitation reaction started with loading the reactor with the microemulsion $(100 \mathrm{~g})$ and then raising temperature to $70^{\circ} \mathrm{C}$, while applying magnetic agitation. After that, the dosing of aqueous solution of $\mathrm{NaOH}$, prepared at two concentrations (20.8 and $41.6 \mathrm{wt} . \%$ ), was started using a calibrated dosing pump KdScientific KDS-210 with a standard deviation less than $1 \%$. Three dosing times of this solution $(15,30$, and $100 \mathrm{~min})$ and the addition by shooting (1 min) were assayed. After dosing was over, the completion reaction was allowed to proceed for $30 \mathrm{~min}$ (postaddition time) and then acetone was added to precipitate the solids in the final reaction mixture. Afterward, the precipitate was washed at least seven times with water-acetone (81/19, wt./wt.) and then dried.

2.3. Characterization. Electrical conductivities of a series of samples with composition inside the one-phase region were measured at $70^{\circ} \mathrm{C}$ and $1 \mathrm{kHz}$ with a Hach Sension 5 conductivity meter. Rheological behavior of some of those samples was determined in an oscillating rheometer Paar Physica UDS 200 using a concentric-cylinder configuration. $\mathrm{X}$-ray analysis of the powders was carried out with a Siemens D-5000 diffractometer using $\mathrm{Cu}-\mathrm{K}_{\alpha}(\lambda=1.5418 \AA)$ as incident radiation. The size and morphology of the particles were determined in a JEOL JSM-7401F scanningtransmission electron microscope (STEM), for which samples were prepared by dispersing the resulting powders in acetone with ultrasonication and then depositing the dispersion on a copper grid.

\section{Results and Discussion}

According to our findings reported elsewhere [25], the partial phase diagram of the system AOT/SDS (2/1, wt./wt.), $0.7 \mathrm{M}$ $\mathrm{Zn}\left(\mathrm{NO}_{3}\right)_{2} \cdot 6 \mathrm{H}_{2} \mathrm{O}$ aqueous solution and toluene at $70^{\circ} \mathrm{C}$ shows a transparent, single phase $(1 \theta)$ region, which extends from the toluene-rich part toward the central part of the diagram. This suggests that at least a part of this region corresponds to microemulsions. To choose a bicontinuous microemulsion composition in which to perform the precipitation reactions, measurements of electrical conductivity and rheological behavior at $70^{\circ} \mathrm{C}$ were carried out. For this, a series of samples with aqueous phase concentrations between 5 and $40 \mathrm{wt} . \%$ and a fixed ratio surfactants/toluene 60/40 (wt./wt.) were prepared. This ratio was chosen because of all of the samples prepared using it are inside the single 


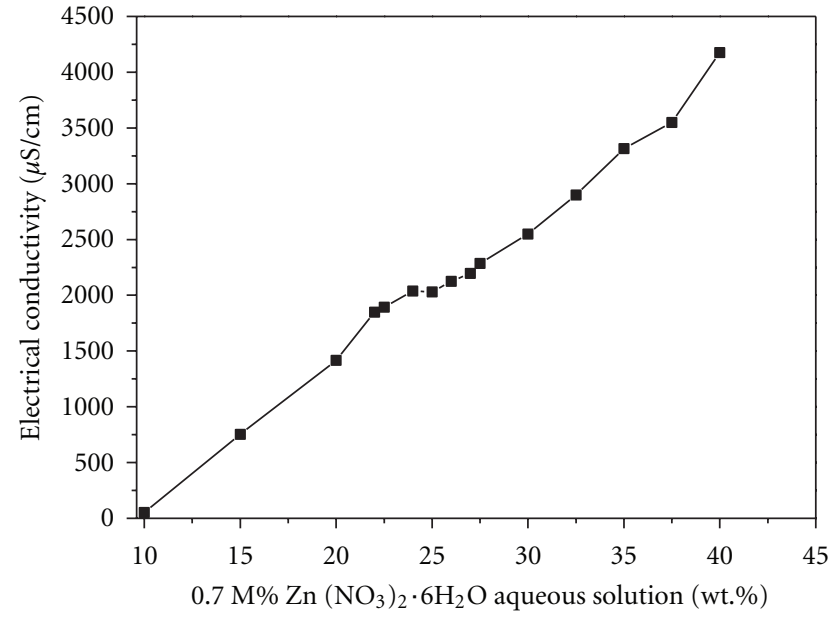

FIgURE 1: Electrical conductivities at $70^{\circ} \mathrm{C}$ of microemulsions at different concentrations of $0.7 \mathrm{M} \mathrm{Zn}\left(\mathrm{NO}_{3}\right)_{2} \cdot 6 \mathrm{H}_{2} \mathrm{O}$ aqueous solution at a fixed ratio surfactants/toluene 60/40 (wt./wt.).

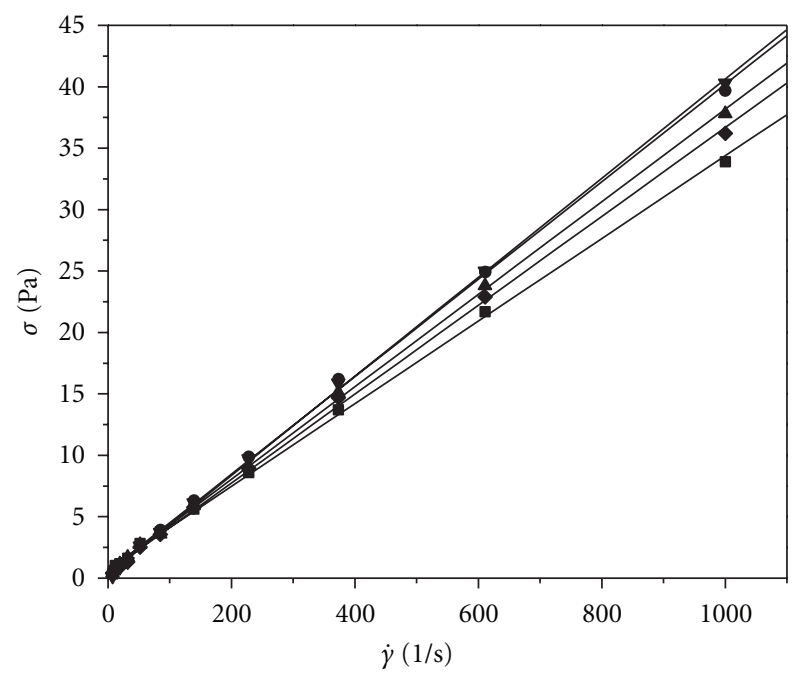

Figure 2: Shear stress $(\sigma)$ as function of shear rate $(\dot{\gamma})$ at $70^{\circ} \mathrm{C}$ for samples prepared with $30(\boldsymbol{\nabla}), 32.5(\boldsymbol{\vee}), 35(\boldsymbol{\Delta}), 37.5(\boldsymbol{\nabla})$, and 40 wt.\% (•) of $0.7 \mathrm{M} \mathrm{Zn}\left(\mathrm{NO}_{3}\right)_{2} \cdot 6 \mathrm{H}_{2} \mathrm{O}$ aqueous solution.

phase region up to $42 \mathrm{wt} . \%$ aqueous phase. The conductivity results are shown in Figure 1. Conductivity values as high as $\approx 700 \mu \mathrm{S} / \mathrm{cm}$ at $15 \%$ aqueous phase, which grows almost linearly as the aqueous phase concentration increases, up to values higher than $4,000 \mu \mathrm{S} / \mathrm{cm}$ at $40 \%$, can be seen here. The large conductivity values and the position of the samples composition in the medium-high part of the diagram rule out they are reverse microemulsions. This type of microemulsions shows very low electrical conductivities because of its discontinuous nanostructure [26, 27]. In contrast, bicontinuous microemulsions show higher capacity for conducting electrical current as a result of having a continuous aqueous phase [27-31]. In spite of their transparency and high capacity for conducting electrical current, not all the measured samples with aqueous phase concentration higher than $15 \%$ are bicontinuous microemulsions. This is because it is well known that systems with high surfactant concentrations (typically $>45-50 \%$ ) would form lamellar systems, such as liquid crystals. The identification of the bicontinuous microemulsions could be carried out based on the rheological behavior of those samples. It is known that microemulsions are Newtonian fluids with relatively low viscosities [32], in contrast with the non-Newtonian behavior and high viscosities of lamellar systems [33].

The graphs of shear stress $(\sigma)$ versus shear rate $(\dot{\gamma})$ for samples prepared with the fixed ratio surfactants/toluene $60 / 40$, wt./wt. and $30,32.5,35,37.5$, and $40 \mathrm{wt} . \%$ of $0.7 \mathrm{M}$ $\mathrm{Zn}\left(\mathrm{NO}_{3}\right)_{2} \cdot 6 \mathrm{H}_{2} \mathrm{O}$ aqueous solution are shown in Figure 2. Samples with aqueous phase concentrations lower than $30 \%$ were not measured because they were not interesting for our work. In all cases, experimental data in the graphs of Figure 2 were fitted to a straight line passing through the origin with a correlation factor $>0.99$, thus illustrating the Newtonian behavior over the shear rate studied. This behavior arises from the fact that a microemulsion is actually a fluctuating entity in dynamic equilibrium with a very short time and length scale for rearrangement after a perturbation [33]. Thus, the main relaxation process in microemulsions is very fast, not affecting viscosity, at least at the upper limit of the shear rate studied. In accordance with Newton's Law of viscosity, the viscosity of the samples can be determined from the slopes of the straight lines in Figure 2 . At $70^{\circ} \mathrm{C}$, the samples show relatively low viscosities, ranging between 34 and $40 \mathrm{cP}$. From the electrical conductivity and rheological measurements, it was concluded that those samples with the fixed ratio surfactants/toluene 60/40, wt./wt. and concentrations of $0.7 \mathrm{M} \mathrm{Zn}\left(\mathrm{NO}_{3}\right)_{2} \cdot 6 \mathrm{H}_{2} \mathrm{O}$ aqueous solution between 30 and $40 \mathrm{wt} . \%$ are bicontinuous microemulsions. From here, a bicontinuous microemulsion with $32.5 \mathrm{wt}$ \% aqueous phase was chosen for carrying out the precipitation reactions.

All the precipitation reactions in which only $\mathrm{ZnO}$ was obtained rendered a white powder at the end of the process. Figure 3 shows the X-ray diffraction pattern (XRDP) of the final products obtained in set 1 of precipitation reactions using the $20.8 \mathrm{wt} . \% \mathrm{NaOH}$ solution. Here, the patterns of the product obtained when $\mathrm{NaOH}$ solution was added by shooting (Figure 3(a)) showed only those characteristic peaks corresponding to $\mathrm{ZnO}$ with a hexagonal wurtzite crystal structure, space group $P 63 m c$, as indicated by the XRDP of $\mathrm{ZnO}$ (Figure 3(f)), which was taken from literature $[12,34]$. XRDP of the rest of the products showed in addition the main characteristic peaks of $\mathrm{Zn}\left(\mathrm{NO}_{3}\right)_{2}$ (arrows in Figures $3(\mathrm{~b}), 3(\mathrm{c})$, and 3(d)) in accordance with its XRDP, which was taken from the library of our X-ray diffractometer. In contrast, Figure 4 shows that when $41.6 \mathrm{wt} . \% \mathrm{NaOH}$ solution was used, all of the products display only the peaks of $\mathrm{ZnO}$ with a hexagonal wurtzite crystal structure, no matter the dosing times used in precipitation reactions. Furthermore, the absence of peaks different to those characteristic of $\mathrm{ZnO}$ in Figures 3(a) and 4 suggests that high-purity $\mathrm{ZnO}$ particles were obtained. XRDPs (not shown) of the products obtained in the replica of precipitation reactions (set 2) are similar to those of set 1 shown in Figures 3 and 4. 


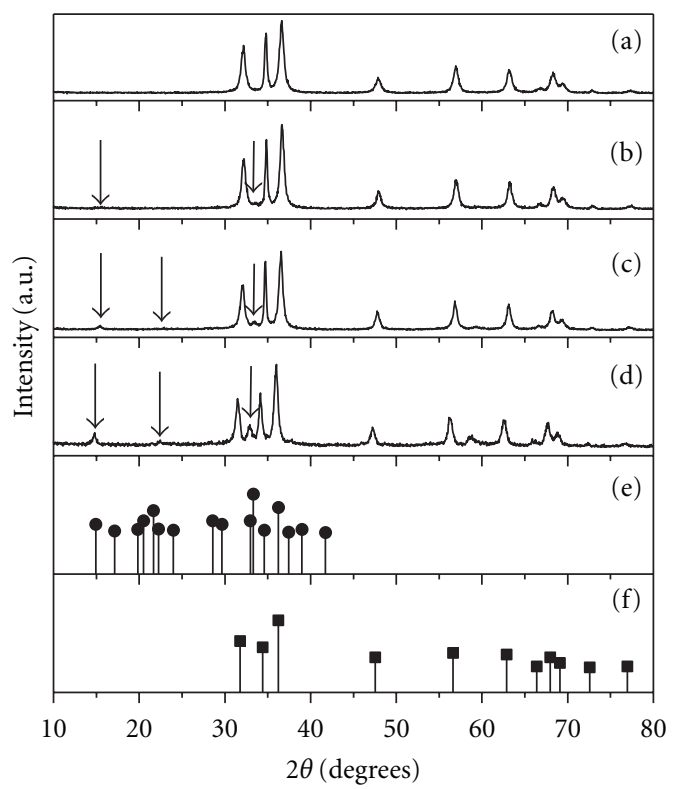

FIGURE 3: XRDPs for samples obtained from precipitation using $20.8 \% \mathrm{NaOH}$ aqueous solution added by shooting (a) and at different dosing times: (b) 15; (c) 30; (d) 100 min. Standard patterns of $\mathrm{Zn}\left(\mathrm{NO}_{3}\right)_{2}$ (e) and $\mathrm{ZnO}$ (f) are included. Arrows indicate the main characteristics peaks of $\mathrm{Zn}\left(\mathrm{NO}_{3}\right)_{2}$.

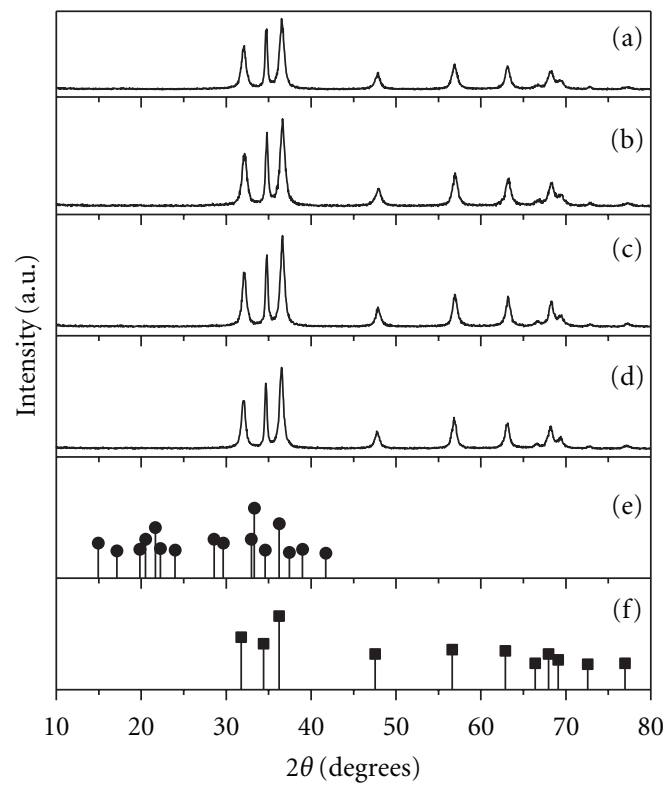

FIGURE 4: XRDPs for samples obtained from precipitation using $41.6 \% \mathrm{NaOH}$ aqueous solution added by shooting (a) and at different dosing times: (b) 15; (c) 30; (d) $100 \mathrm{~min}$. Standard patterns of $\mathrm{Zn}\left(\mathrm{NO}_{3}\right)_{2}$ (e) and $\mathrm{ZnO}$ (f) are included.

The absence of $\mathrm{Zn}\left(\mathrm{NO}_{3}\right)_{2}$ peaks in the XRDP of the samples in Figures 3(a) and 4 can be ascribed to (i) that precipitation reaction was practically completed, or (ii) that the precipitation reaction was not completed but all the residual $\mathrm{Zn}\left(\mathrm{NO}_{3}\right)_{2}$ was eliminated throughout the washing process. Because all the products were subjected to the same washing process, it is believed that when no
$\mathrm{Zn}\left(\mathrm{NO}_{3}\right)_{2}$ peaks appear in the XRDPs the precipitation reaction was completed. The data indicate that when using the $\mathrm{NaOH} / \mathrm{Zn}\left(\mathrm{NO}_{3}\right)_{2}$, stoichiometric ratio $(20.8 \% \mathrm{NaOH}$ solution) the precipitation reaction was completed only when this solution was added by shooting. On the other hand, all the precipitation reactions were completed when twice the $\mathrm{NaOH} / \mathrm{Zn}\left(\mathrm{NO}_{3}\right)_{2}$ stoichiometric ratio $(41.6 \%$ $\mathrm{NaOH}$ solution) was used, no matter the dosing times. This behavior could be due to the higher concentration of precipitating agent in the reaction sites, when $41.6 \mathrm{wt} . \% \mathrm{NaOH}$ solution was used. This condition accelerates the reaction rate. It is possible that the precipitation reaction performed with 20.8 wt. $\% \mathrm{NaOH}$ solution was also completed when this solution was added by shooting, because of the high $\mathrm{NaOH}$ concentration in the reaction sites, as a result of the rapid addition of the precipitating agent.

Something that draws attention is the direct synthesis of $\mathrm{ZnO}$ achieved in this work. Lim et al. [17] reported the precipitation of $\mathrm{Zn}(\mathrm{OH})_{2}$ in bicontinuous microemulsion, which was further calcined for obtaining $\mathrm{ZnO}$. In contrast with us, these authors used lower reagent concentration: $0.5 \mathrm{M}$ aqueous solution $\mathrm{Zn}\left(\mathrm{NO}_{3}\right)_{2}$ and $1.0 \mathrm{M}$ aqueous solution precipitating agent (ammonium hydroxide). We used 0.7 and $10.0 \mathrm{M}$, respectively. In addition, they carried out the precipitation reaction at room temperature. From this, it is clear that our reaction conditions were drastic enough for immediate oxidation of $\mathrm{Zn}(\mathrm{OH})_{2}$, formed by the reaction of $\mathrm{Zn}\left(\mathrm{NO}_{3}\right)_{2}$ and $\mathrm{NaOH}$, to form $\mathrm{ZnO}$ [12]. In fact, $\mathrm{Zhu}$ and Zhou [12] reported the direct synthesis of $\mathrm{ZnO}$ nanoparticles in solid-state reaction only when they used a molar ratio $\mathrm{NaOH} / \mathrm{ZnSO}_{4} \cdot 7 \mathrm{H}_{2} \mathrm{O}$ as high as 4 .

Table 1 shows the mean productivities and yields of those precipitation reactions (sets 1 and 2) in which only $\mathrm{ZnO}$ was obtained. Data in this table indicate productivities between 1.3 and $1.6 \mathrm{~g}$ of $\mathrm{ZnO}$ particles per $100 \mathrm{~g}$ of microemulsion and reaction yields relatively high (83-89\%). Furthermore, these indicators were not affected by the studied variations in the conditions of the precipitation reactions. Productivities in this study are significantly higher than the highest productivity value, $0.7 \mathrm{~g}$ of $\mathrm{ZnO}$ particles per $100 \mathrm{~g}$ of microemulsion, calculated from data reported in the literature on preparation of $\mathrm{ZnO}$ nanoparticles via microemulsions using commercial surfactants [17]. While there is a higher productivity value, $2.0 \mathrm{~g}$ of $\mathrm{ZnO}$ particles per $100 \mathrm{~g}$ of microemulsion, also calculated from those data, the microemulsion used was stabilized with a noncommercial surfactant, which requires a somewhat complex synthesis [16].

Micrographs of some of the final products from the precipitation reactions (set 1 ) are displayed in Figures 5 and 6. Micrographs in Figure 5 correspond to precipitations performed with the addition by shooting of the $20.8 \%$ (Figure 5(a)) and 41.6\% (Figure 5(b)) $\mathrm{NaOH}$ solution. Particles in these figures show an acicular rod-like morphology. To characterize these particles, diameter and length of more than 500 of them were measured from different micrographs of each of the samples. In this and in the rest of the following measurements, the largest diameter of the acicular particles was taken. Histograms of distribution of diameters and lengths are also included in Figure 5. Particle size data in 
TABLE 1: Mean yields and productivities of those reactions (in duplicate) in which only $\mathrm{ZnO}$ was obtained at two concentrations of $\mathrm{NaOH}$ solution.

\begin{tabular}{|c|c|c|c|c|c|c|c|c|}
\hline \multirow{2}{*}{$\begin{array}{l}\text { Dosing } \\
\text { time (min) }\end{array}$} & \multicolumn{4}{|c|}{20.8 wt. $\%$} & \multicolumn{4}{|c|}{41.6 wt. $\%$} \\
\hline & $\begin{array}{l}\text { Final product } \\
(\mathrm{g})\end{array}$ & $\begin{array}{l}\text { Theoretical } \\
\text { product (g) }\end{array}$ & $\begin{array}{l}\text { Mean yield } \\
(\%)\end{array}$ & Mean Prod. ${ }^{a}$ & $\begin{array}{l}\text { Final product } \\
(\mathrm{g})\end{array}$ & $\begin{array}{l}\text { Theoretical } \\
\text { product }(\mathrm{g})\end{array}$ & $\begin{array}{l}\text { Mean Yield } \\
(\%)\end{array}$ & Mean Prod. ${ }^{a}$ \\
\hline 1 & $\begin{array}{l}1.5012 \\
1.6020\end{array}$ & $\begin{array}{l}1.8326 \\
1.8326\end{array}$ & $84.67 \pm 3.88$ & $1.55 \pm 0.07$ & $\begin{array}{l}1.5771 \\
1.5597\end{array}$ & $\begin{array}{l}1.8326 \\
1.8373\end{array}$ & $85.48 \pm 0.83$ & $1.56 \pm 0.01$ \\
\hline 15 & - & - & - & - & $\begin{array}{l}1.5237 \\
1.5326\end{array}$ & $\begin{array}{l}1.8351 \\
1.8373\end{array}$ & $83.23 \pm 0.28$ & $1.53 \pm 0.007$ \\
\hline 30 & - & - & - & - & $\begin{array}{l}1.5137 \\
1.5263 \\
\end{array}$ & $\begin{array}{l}1.8377 \\
1.8326 \\
\end{array}$ & $82.83 \pm 0.7$ & $1.52 \pm 0.007$ \\
\hline 100 & - & - & - & - & $\begin{array}{l}1.5909 \\
1.6653\end{array}$ & $\begin{array}{l}1.8349 \\
1.8343\end{array}$ & $88.74 \pm 2.9$ & $1.62 \pm 0.04$ \\
\hline
\end{tabular}

${ }^{\mathrm{a}} \mathrm{g}$ of $\mathrm{ZnO} / 100 \mathrm{~g}$ of microemulsion.

histograms allowed us to calculate number-average diameter $\left(D_{n}\right)$ values of 9.0 and $8.5 \mathrm{~nm}$ and average lengths of 30.2 and $30.6 \mathrm{~nm}$ for the precipitation products with 20.8 and $41.6 \%$ $\mathrm{NaOH}$ solution, respectively.

Figure 6 displays micrographs from products of some of the precipitations carried out with $41.6 \% \mathrm{NaOH}$ solution (set 1). Figures 6(a) and 6(b) correspond to 15 and $100 \mathrm{~min}$ dosing time, respectively. An inspection of the particles in Figure 6(a) shows an acicular rod-like morphology. Measurements of diameter and length of around 300 particles from different micrographs are reflected in the histograms included in Figure 6(a). From here, values for $D_{n}$ and average length of 9.5 and $23.3 \mathrm{~nm}$, respectively, were obtained. The average dimensions of these particles are somewhat similar to those obtained when using the same $\mathrm{NaOH}$ solution concentration, but added by shooting (Figure 5(b)). On the other hand, Figure 6(b) shows that in spite of a predominance of acicular rod-like morphology, there are also plate, elongated plate, and spheroidal morphologies. Because of this variety of structures, only particle diameter measurements were carried out on the corresponding micrographs. From the counting of around 200 particles, the histogram in Figure 6(b) was elaborated and a $D_{n}$ of $21.1 \mathrm{~nm}$ was obtained.

An inspection of the micrographs (not shown) of the final products from set 2 of precipitation reactions confirms the acicular rod-like morphology of the particles obtained when $\mathrm{NaOH}$ solution at the two studied concentrations was added by shooting and when the $41.6 \% \mathrm{NaOH}$ solution was dosed in $15 \mathrm{~min}$. The mixture of plate, elongatedplate, spheroidal, and acicular rod-like morphologies with predominance of the latter was also observed in the final product obtained using the $41.6 \% \mathrm{NaOH}$ solution dosed in $100 \mathrm{~min}$.

A similar procedure to that described above was performed using the micrographs of the final products from set 2 of precipitation reactions. The particle average dimensions calculated from the $D_{n}$ and average lengths values obtained in set 1 and 2 of precipitation reactions are shown in Table 2. Data in this table and the micrographs in Figure 5 indicate that the structure and size of nanoparticles were not affected by the increase in $\mathrm{NaOH}$ solution concentration, at least when this solution was added by shooting. Moreover, it appears that particle size increases as the dosing time of the
TABLE 2: Average dimensions of $\mathrm{ZnO}$ nanoparticles obtained at two concentrations of $\mathrm{NaOH}$ solutions.

\begin{tabular}{lcccc}
\hline $\begin{array}{l}\text { Dosing } \\
\text { time }(\mathrm{min})\end{array}$ & \multicolumn{2}{c}{$20.8 \mathrm{wt} \%$} & \multicolumn{2}{c}{$41.6 \mathrm{wt. \%}$} \\
& $D_{n}(\mathrm{~nm})$ & $\begin{array}{c}\text { Length } \\
(\mathrm{nm})\end{array}$ & $D_{n}(\mathrm{~nm})$ & $\begin{array}{c}\text { Length } \\
(\mathrm{nm})\end{array}$ \\
\hline 1 & $8.6 \pm 0.6$ & $26.4 \pm 11.0$ & $8.3 \pm 0.3$ & $29.6 \pm 1.4$ \\
15 & - & - & $9.7 \pm 0.2$ & $24.6 \pm 1.8$ \\
100 & - & - & $20.4 \pm 0.1$ & - \\
\hline
\end{tabular}

$\mathrm{NaOH}$ solution strongly increases, that is, as the total processing time strongly augments. Thus, when $\mathrm{NaOH}$ solution is added by shooting, total processing time is $31 \mathrm{~min}$, including the postaddition time. In contrast, when this solution is dosed in $100 \mathrm{~min}$, total processing time is $130 \mathrm{~min}$. This difference could be very important in determining particle size, because of the postulated mechanism for the formation and growth of particles in bicontinuous microemulsions [23]. According to this mechanism, when $\mathrm{NaOH}$ solution is dosed on the bicontinuous microemulsion, this solution containing $\mathrm{Na}^{+}$and ${ }^{-} \mathrm{OH}$ ions diffuses into the channels in which $\mathrm{Zn}^{++}$ and ${ }^{-} \mathrm{NO}_{3}$ ions are confined. Under these conditions, the precipitation reaction occurs forming $\mathrm{Zn}(\mathrm{OH})_{2}$ molecules, which oxide to $\mathrm{ZnO}$. A fraction of these molecules clusters generating nuclei in some points of the channels. Thereafter, nuclei can grow by two mechanisms: (i) recruiting molecules or clusters of $\mathrm{ZnO}$ and (ii) by aggregation as a consequence of interparticle collisions. These collisions occur between neighboring particles inside the channels of the microemulsion, as well as between particles from different channels when these channels collide. Unlike precipitation in reverse microemulsions, where particles are protected by a surfactant film and so, usually only a small fraction of the interparticle collisions leads to aggregation [35], particles within the channels of bicontinuous microemulsions are not protected with any surfactant film. Thus, compared with what happens in reverse microemulsion precipitation, a greater particle aggregation should be expected in precipitation in bicontinuous microemulsion, mainly when total processing times are long. The formation of acicular morphologies suggests a one-dimensional aggregation, which also has been observed in chemical coprecipitation of $\mathrm{ZnO}$ nanoparticles, where 


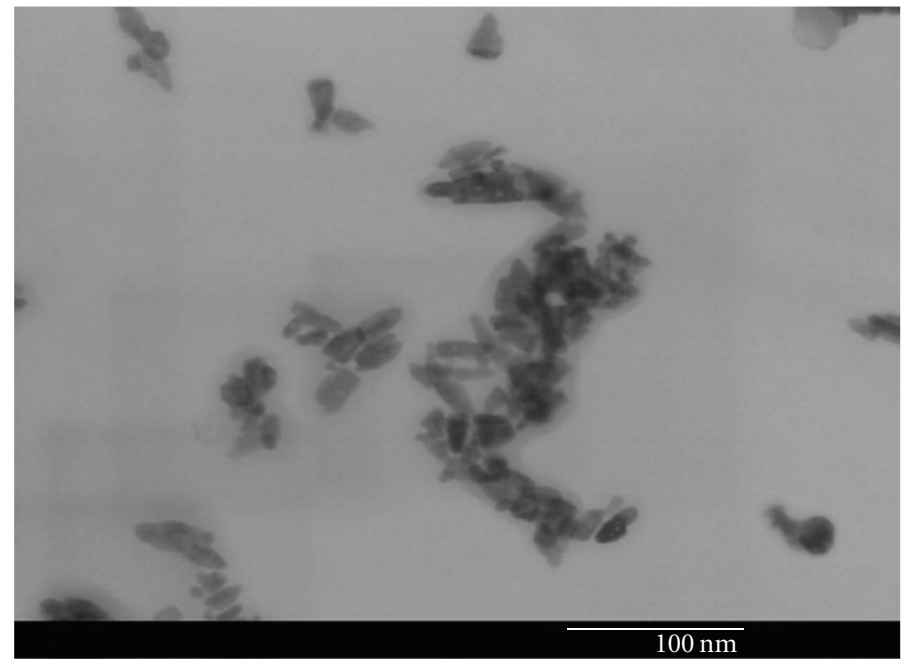

(a)

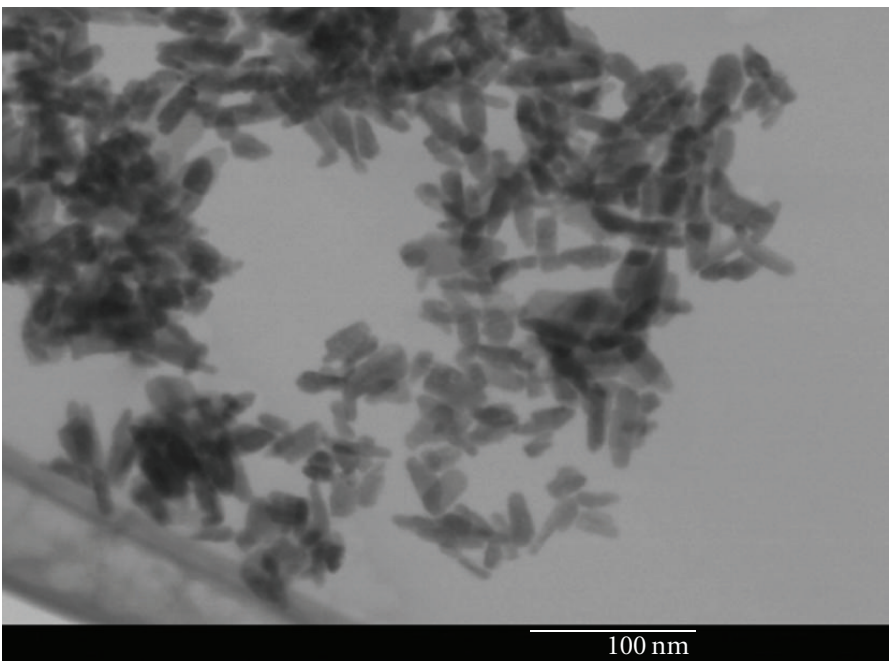

(b)
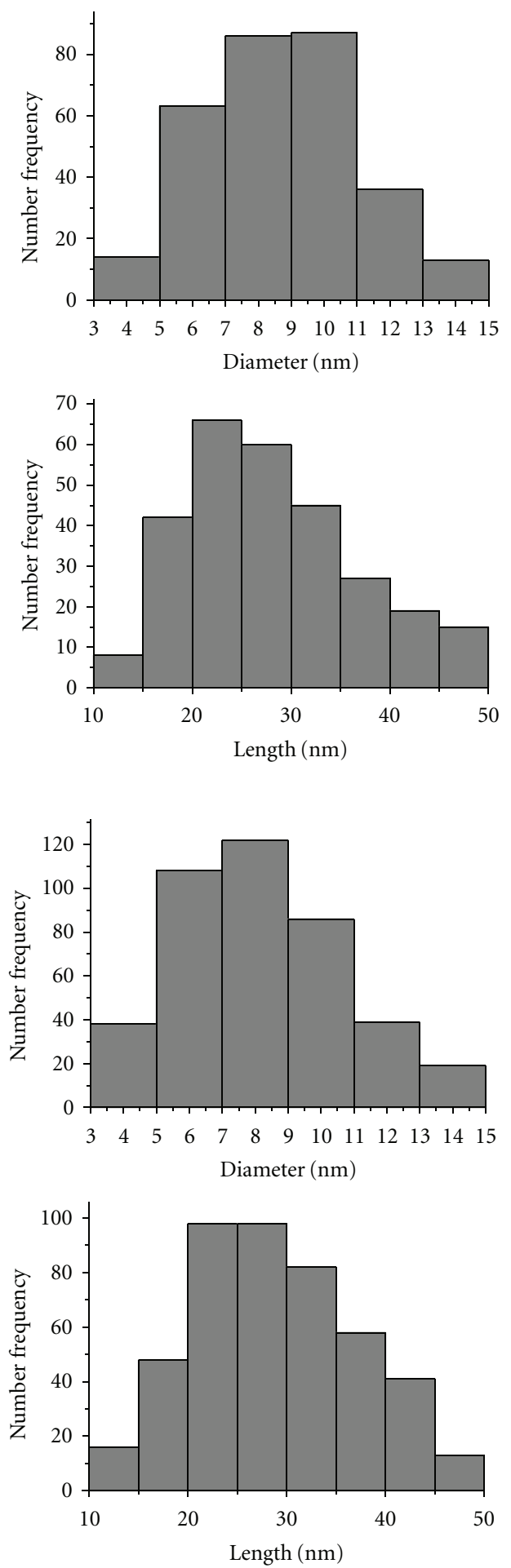

FIGURE 5: STEM micrographs of samples obtained from precipitation using 20.8 (a) and 41.6\% (b) NaOH aqueous solution added by shooting (set 1). Histograms of particle diameter and length are included.

larger particles were obtained [34]. It is believed that the smaller particle sizes obtained in precipitation in bicontinuous microemulsions, compared with those obtained in chemical coprecipitation [34] and solid-state reaction [12] arise from the protection that the surfactant film gives during the interchannel collisions, reducing the frequency of channel fusion-fission process and, as a consequence, particle aggregation. 


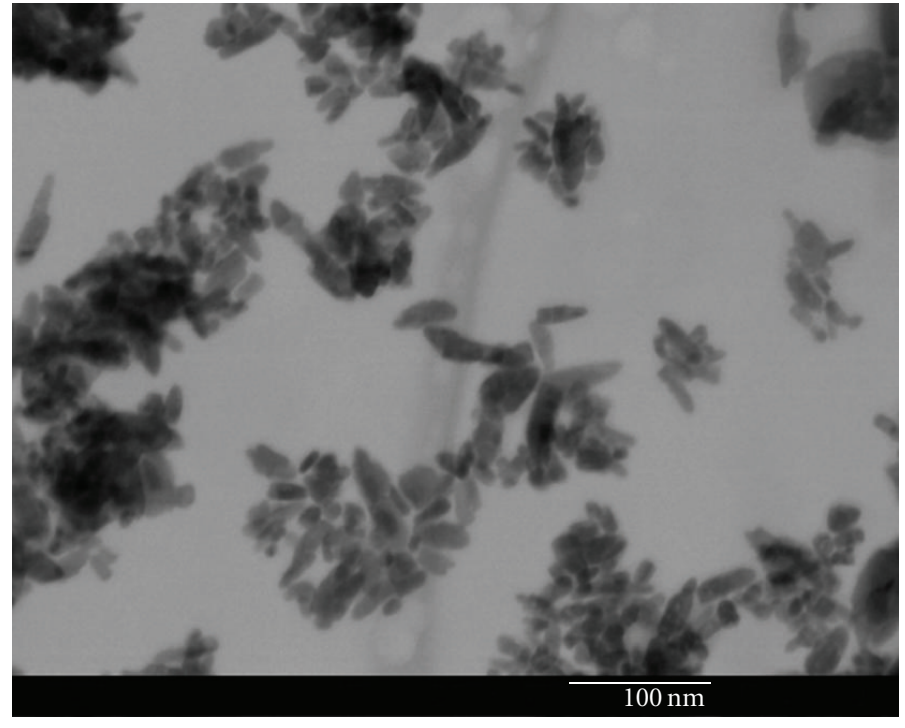

(a)

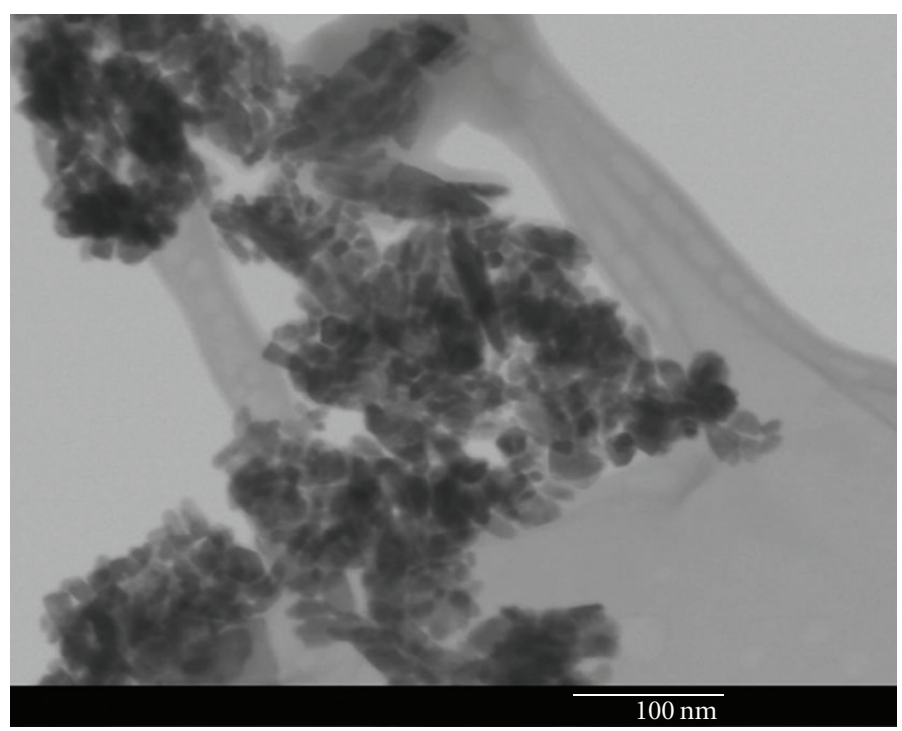

(b)
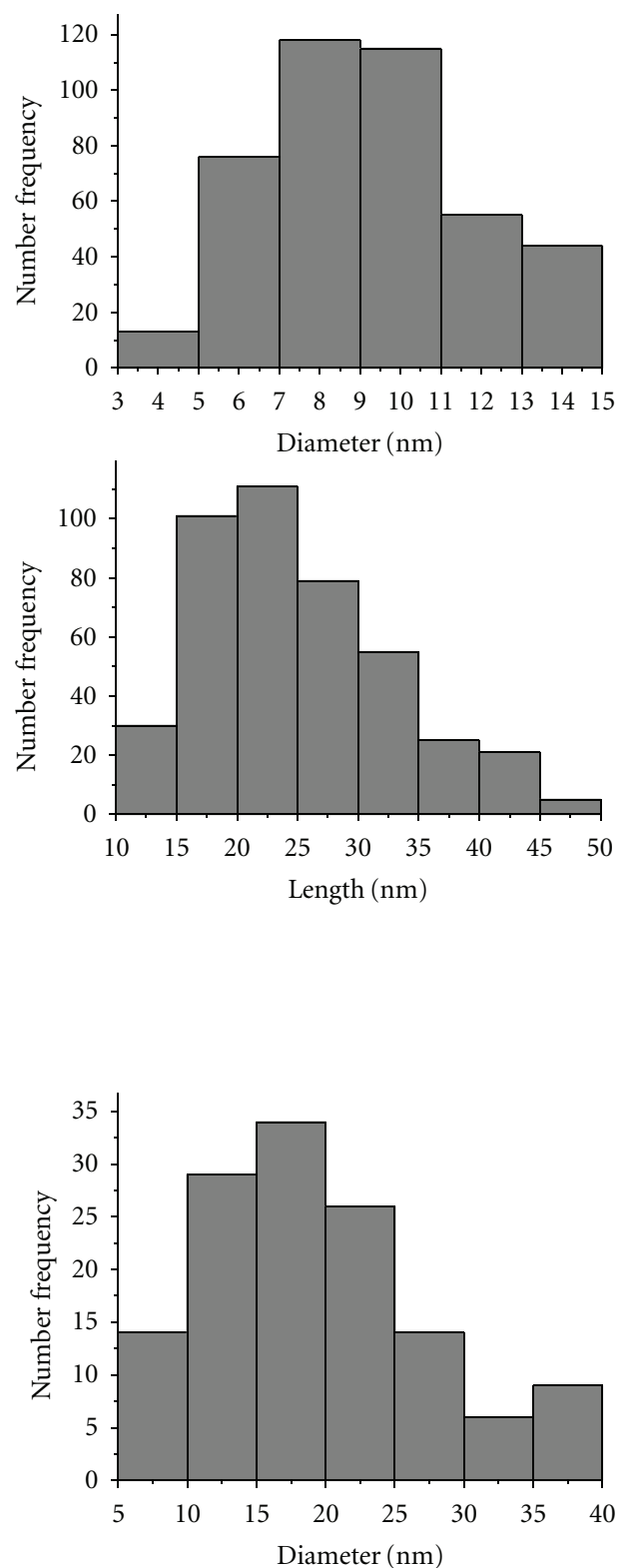

FIGURE 6: STEM micrographs of samples obtained from precipitation using $41.6 \% \mathrm{NaOH}$ aqueous solution at dosing times of 15 (a) and $100 \mathrm{~min}$ (b) (set 1). Histograms of particle diameter and length (the latter only for the sample at 15 min of dosing time) are included.

The mean grain sizes of those particles obtained in set 1 and 2 of precipitation reactions were calculated by using data from their XRDPs and the well-known Scherrer equation, which is represented as

$$
d=\frac{K \lambda}{\beta \cos \theta},
$$

where $d$ is the mean diameter of grain in $\mathrm{nm} ; K$ is the dimensional factor $(0.9) ; \lambda$ is the $\mathrm{X}$-ray wavelength
$(0.154 \mathrm{~nm}) ; \beta$ is the line broadening at half the maximum intensity in radians, and $\theta$ is Bragg's angle. $d$ values of $16.8 \pm 0.2$ and $15.1 \pm 0.1 \mathrm{~nm}$ for the precipitations performed with the addition by shooting of the $20.8 \%$ and $41.6 \% \mathrm{NaOH}$ solution, respectively, were obtained. On the other hand, when the latter was dosed in 15 and in $100 \mathrm{~min}$, the $d$ values were $14.7 \pm 0.2$ and $18.6 \pm 0.1 \mathrm{~nm}$, respectively. These results agree with the average values shown in Table 2, suggesting that the larger final particle size results from the aggregation of the $\mathrm{ZnO}$ smaller grains. 


\section{Conclusions}

Precipitation at $70^{\circ} \mathrm{C}$ in bicontinuous microemulsions containing a $\mathrm{Zn}\left(\mathrm{NO}_{3}\right)_{2} \cdot 6 \mathrm{H}_{2} \mathrm{O}$ aqueous solution carried out adding an $\mathrm{NaOH}$ aqueous solution, allowed us to obtain $\mathrm{ZnO}$ nanoparticles directly, avoiding the calcination step. These particles display a predominant acicular rod-like morphology with a hexagonal wurtzite crystal structure. When $\mathrm{NaOH}$ solution is added by shooting, particles with average diameters and lengths around 8.5 and $30 \mathrm{~nm}$, respectively, were obtained. It is thought that the surfactant film on the microemulsion channels gives some protection during interchannel collisions, decreasing particle aggregation. When the dosing time of $\mathrm{NaOH}$ solution was very long, larger particles with average diameters close to $20 \mathrm{~nm}$ and morphologies like plates, elongated plates, and spheroids, in addition to acicular morphology, were obtained. It is believed that this morphology results from one-dimensional aggregation inside of microemulsion channels. Productivities between 1.3 and $1.6 \mathrm{~g}$ of $\mathrm{ZnO}$ particles per $100 \mathrm{~g}$ of microemulsion were obtained, that is, much higher than those typical of $\mathrm{ZnO}$ preparation via reverse microemulsions.

\section{Acknowledgments}

The National Council of Science and Technology (CONACyT) supported this research through grant 2007-84009. The authors are grateful to Alejandro Espinoza and Blanca Huerta for their technical assistance in characterization work.

\section{References}

[1] H. S. Qian, S. H. Yu, J. Y. Gong, L. B. Luo, and L. L. Wen, "Growth of $\mathrm{ZnO}$ crystals with branched spindles and prismatic whiskers from $\mathrm{Zn}_{3}(\mathrm{OH})_{2} \mathrm{~V}_{2} \mathrm{O}_{7} \mathrm{H}_{2} \mathrm{O}$ nanosheets by a hydrothermal route," Crystal Growth and Design, vol. 5, no. 3, pp. 935-939, 2005.

[2] E. Tang, G. Cheng, X. Pang, X. Ma, and F. Xing, "Synthesis of nano- $\mathrm{ZnO} /$ poly(methyl methacrylate) composite microsphere through emulsion polymerization and its UV-shielding property," Colloid and Polymer Science, vol. 284, no. 4, pp. 422428, 2006.

[3] J. Sawai, H. Igarashi, A. Hashimoto, T. Kokugan, and M. Shimizu, "Evaluation of growth inhibitory effect of ceramics powder slurry on bacteria by conductance method," Journal of Chemical Engineering of Japan, vol. 28, no. 3, pp. 288-293, 1995.

[4] V. Khrenov, M. Klapper, M. Koch, and K. Müllen, "Surface functionalized $\mathrm{ZnO}$ particles designed for the use in transparent nanocomposites," Macromolecular Chemistry and Physics, vol. 206, no. 1, pp. 95-101, 2005.

[5] I. A. Toutorski, T. E. Tkachenko, B. V. Pokidko, N. I. Maliavski, and V. I. Sidorov, "Mechanical properties and structure of zinc-containing latex-silicate composites," Journal of Sol-Gel Science and Technology, vol. 26, no. 1-3, pp. 505-509, 2003.

[6] L. Wang and M. Muhammed, "Synthesis of zinc oxide nanoparticles with controlled morphology," Journal of Materials Chemistry, vol. 9, no. 11, pp. 2871-2878, 1999.
[7] J. E. Rodríguez-Paéz, A. C. Caballero, M. Villegas, C. Moure, P. Durán, and J. F. Fernández, "Controlled precipitation methods: formation mechanism of $\mathrm{ZnO}$ nanoparticles," Journal of the European Ceramic Society, vol. 21, no. 7, pp. 925-930, 2001.

[8] M. Purica, E. Budianu, E. Rusu, M. Danila, and R. Gavrila, "Optical and structural investigation of $\mathrm{ZnO}$ thin films prepared by chemical vapor deposition (CVD)," Thin Solid Films, vol. 403-404, pp. 485-488, 2002.

[9] N. Audebrand, J. P. Auffrédic, and D. Louër, "X-ray diffraction study of the early stages of the growth of nanoscale zinc oxide crystallites obtained from thermal decomposition of four precursors. General concepts on precursor-dependent microstructural properties," Chemistry of Materials, vol. 10, no. 9, pp. 2450-2461, 1998.

[10] Y. Yang, H. Chen, B. Zhao, and X. Bao, "Size control of $\mathrm{ZnO}$ nanoparticles via thermal decomposition of zinc acetate coated on organic additives," Journal of Crystal Growth, vol. 263, no. 1-4, pp. 447-453, 2004.

[11] C. H. Lu and C. H. Yeh, "Influence of hydrothermal conditions on the morphology and particle size of zinc oxide powder," Ceramics International, vol. 26, no. 4, pp. 351-357, 2000.

[12] Y. Zhu and Y. Zhou, "Preparation of pure ZnO nanoparticles by a simple solid-state reaction method," Applied Physics A: Materials Science and Processing, vol. 92, no. 2, pp. 275-278, 2008.

[13] T. Tani, L. Mädler, and S. E. Pratsinis, "Homogeneous $\mathrm{ZnO}$ nanoparticles by flame spray pyrolysis," Journal of Nanoparticle Research, vol. 4, no. 4, pp. 337-343, 2002.

[14] S. Hingorani, V. Pillai, P. Kumar, M. S. Multani, and D. O. Shah, "Microemulsion mediated synthesis of zinc-oxide nanoparticles for varistor studies," Materials Research Bulletin, vol. 28, no. 12, pp. 1303-1310, 1993.

[15] S. Hingorani, D. O. Shah, and M. S. Multani, "Effect of process variables on the grain growth and microstructure of $\mathrm{ZnO}$ $\mathrm{Bi}_{2} \mathrm{O}_{3}$ varistors and their nanosize $\mathrm{ZnO}$ precursors," Journal of Materials Research, vol. 10, no. 2, pp. 461-467, 1995.

[16] M. Singhal, V. Chhabra, P. Kang, and D. O. Shah, "Synthesis of $\mathrm{ZnO}$ nanoparticles for varistor application using $\mathrm{Zn}$ substituted aerosol OT microemulsion," Materials Research Bulletin, vol. 32, no. 2, pp. 239-247, 1997.

[17] B. P. Lim, J. Wang, S. C. Ng, C. H. Chew, and L. M. Gan, "A bicontinuous microemulsion route to zinc oxide powder," Ceramics International, vol. 24, no. 3, pp. 205-209, 1998.

[18] M. Inoguchi, K. Suzuki, K. Kageyama, H. Takagi, and Y. Sakabe, "Monodispersed and well-crystallized zinc oxide nanoparticles fabricated by microemulsion method," Journal of the American Ceramic Society, vol. 91, no. 12, pp. 3850-3855, 2008.

[19] J. B. Nagy, Handbook of Microemulsión Science and Technology, Marcel Dekker Inc., New York, NY, USA, 1999.

[20] K. Osseo-Asare, Handbook of Microemulsión Science and Technology, Marcel Dekker Inc., New York, NY, USA, 1999.

[21] J. Esquivel, I. A. Facundo, M. E. Treviño, and R. G. López, "A novel method to prepare magnetic nanoparticles: precipitation in bicontinuous microemulsions," Journal of Materials Science, vol. 42, no. 21, pp. 9015-9020, 2007.

[22] A. L. Loo, M. G. Pineda, H. Saade, M. E. Treviño, and R. G. López, "Synthesis of magnetic nanoparticles in bicontinuous microemulsions. Effect of surfactant concentration," Journal of Materials Science, vol. 43, no. 10, pp. 3649-3654, 2008.

[23] P. Y. Reyes, J. A. Espinoza, M. E. Treviño, H. Saade, and R. G. López, "Synthesis of silver nanoparticles by precipitation in 
bicontinuous microemulsions," Journal of Nanomaterials, vol. 2010, Article ID 948941, 7 pages, 2010.

[24] S. Ezrahi, A. Aserin, and N. Garti, Handbook of Microemulsión Science and Technology, Marcel Dekker Inc., New York, NY, USA, 1999.

[25] S. López-Cuenca, M. Rabelero, H. Saade, R. G. López, E. Mendizábal, and J. E. Puig, "High-yield synthesis of zinc oxide nanoparticles from bicontinuous microemulsions," Journal of Nanomaterials, vol. 2011, Article ID 431382, 6 pages, 2011.

[26] H. F. Eicke, M. Borkovec, and B. Das-Gupta, "Conductivity of water-in-oil microemulsions: a quantitative charge fluctuation model," Journal of Physical Chemistry, vol. 93, no. 1, pp. 314317, 1989.

[27] M. Borkovec, H. F. Eicke, H. Hammerich, and B. Das Gupta, "Two percolation processes in microemulsions," Journal of physical chemistry, vol. 92, no. 1, pp. 206-211, 1988.

[28] J. F. Billman and E. W. Kaler, "Structure and phase behavior in five-component microemulsions," Langmuir, vol. 6, no. 3, pp. 611-620, 1990.

[29] A. Maitra, C. Mathew, and M. Varshney, "Closed and open structure aggregates in microemulsions and mechanism of percolative conduction," Journal of Physical Chemistry, vol. 94, no. 13, pp. 5290-5292, 1990.

[30] A. V. Sineva, D. S. Ermolat'ev, and A. V. Pertsov, "Structural transformations in a water- $n$-octane + chloroform-sodium dodecyl sulfate- $n$-pentanol microemulsion," Colloid Journal, vol. 69, no. 1, pp. 89-94, 2007.

[31] L. M. Gan, T. H. Chieng, C. H. Chew, and S. C. Ng, "Microporous polymeric materials from microemulsion polymerization," Langmuir, vol. 10, no. 11, pp. 4022-4026, 1994.

[32] M. Gradzielski and H. Hoffmann, Handbook of Microemulsión Science and Technology, Marcel Dekker Inc., New York, NY, USA, 1999.

[33] C. M. Chen and G. G. Warr, "Rheology of ternary microemulsions," Journal of Physical Chemistry, vol. 96, no. 23, pp. 9492 9497, 1992.

[34] M. Gusatti, J. A. Rosário, G. S. Barroso, C. E.M. Campos, H. G. Riella, and N. C. Kunhen, "Synthesis of $\mathrm{ZnO}$ nanostructures in low reaction temperature," Chemical Engineering Transactions, vol. 17, pp. 1017-1021, 2009.

[35] M. M. Husein and N. N. Nassar, "Nanoparticle preparation using the single microemulsions scheme," Current Nanoscience, vol. 4, no. 4, pp. 370-380, 2008. 

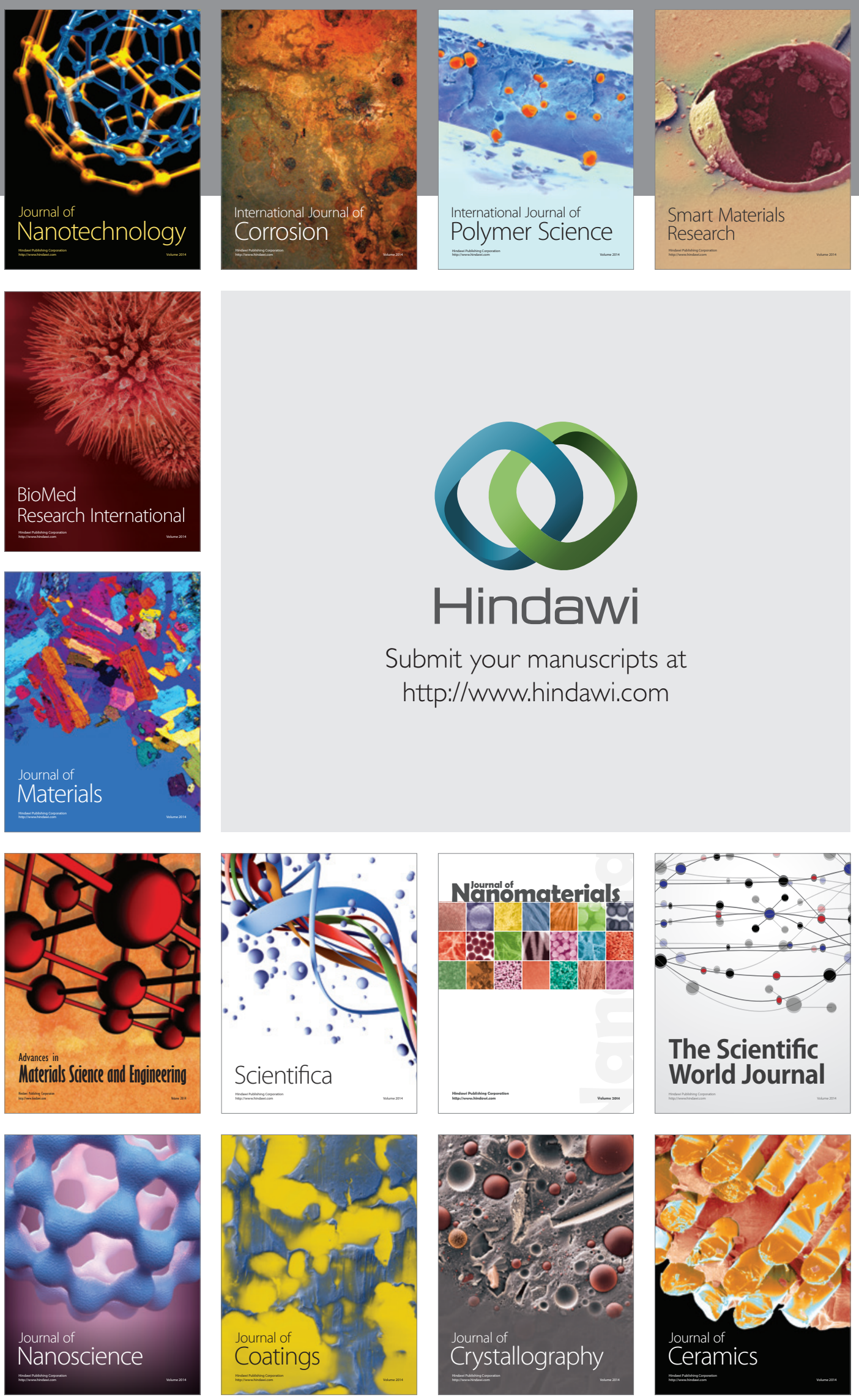

The Scientific World Journal

Submit your manuscripts at

http://www.hindawi.com

\section{World Journal}

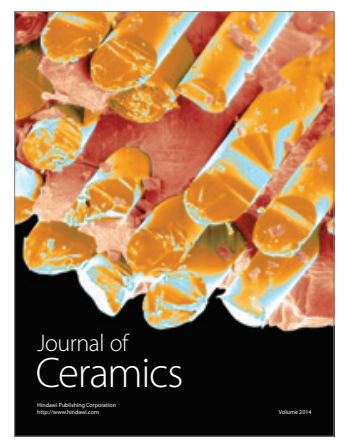

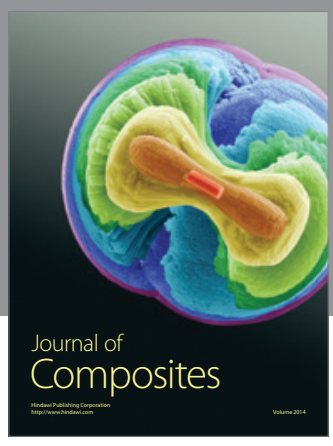
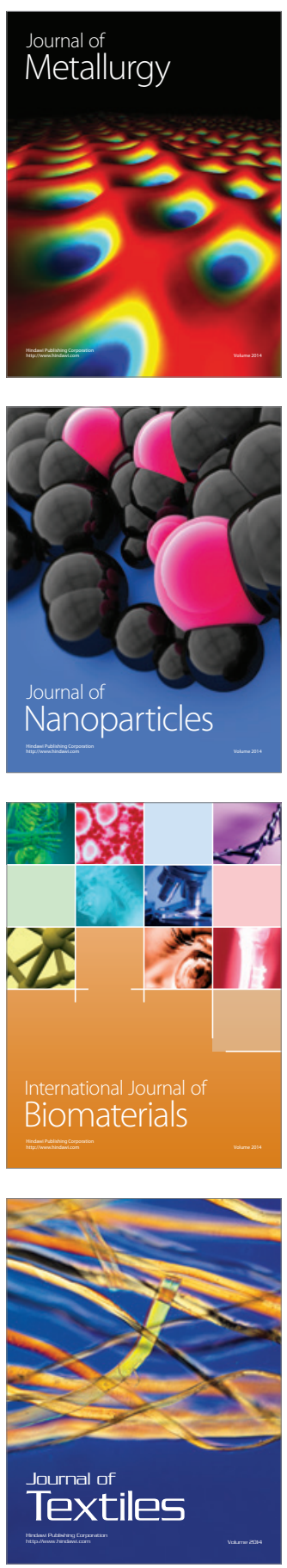